\title{
A importância do viveiro de plantas do jardim botânico de Teresina (PI) como instrumento criador de áreas verdes
}

The importance of the Teresina (PI) botanical garden plant board as a green area creating instrument

La importancia del vivo de plantas del jardín botánico de Teresina (PI) como instrumento creador de áreas verdes

MOEMA TAIS TEIXEIRA BARRADAS Acadêmica de Arquitetura e Urbanismo, UNINOVAFAPI, Brasil. moematais15@gmail.com

PRISCILA BARBOSA NUNES Acadêmica de Arquitetura e Urbanismo, UNINOVAFAPI, Brasil. prisciladernunes@terra.com

LARA CITO LOPES Professor Mestre, UNINOVAFAPI, Brasil laralopes@uninovafapi.edu.br 


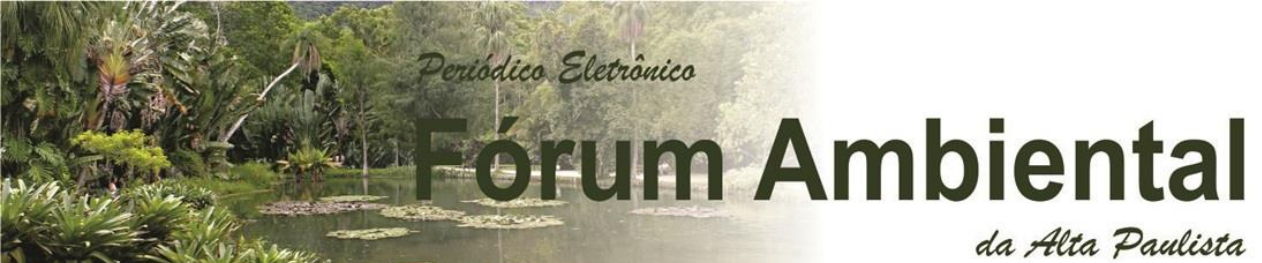

Volume 14, Número 5, 2018

ISSN 1980-0827

RESUMO

As cidades cresceram desordenadamente nas últimas décadas, levando ao processo de urbanização sem planejamento e, consequentemente, ao desmatamento e a falta de reprogramação de novos espaços verdes. Por conta disso, o ambiente vem apresentando modificações importantes e irreversíveis, tornando-se um meio nocivo e impróprio para saúde e bem-estar da população. A criação de espaços urbanos arborizados, além da revitalização sustentável de locais públicos existentes, proporciona uma melhoria na qualidade de vida, benefícios ambientais e sociais. Diante desse panorama apresentado, o objetivo desse estudo foi discutir a importância do viveiro de plantas, dentro do Jardim Botânico de Teresina, enquanto instrumento de criação de áreas verdes e arborizadas, proporcionando sustentabilidade dentro da cidade. Para isso, foram realizadas pesquisas em fontes científicas que retratam tal temática além de pesquisa de campo no viveiro do Jardim Botânico de Teresina. Observou-se que o viveiro de mudas do Jardim Botânico funciona como um instrumento importante no reflorestamento da cidade, em áreas de parques, praças e em projetos de revitalização, com o cultivo de plantas nativas, adaptáveis ao nosso clima. No entanto, é necessária mais infraestrutura no parque e divulgação do viveiro para maior demanda espontânea da população.

PALAVRAS-CHAVE: Áreas verdes. Arborização. Sustentabilidade.

\section{ABSTRACT}

Cities have grown disorderly in the last decades, due to the unplanned urbanization and, consequently, deforestation and the lack of reprogramming of new green spaces. Because of this, the environment has undergone important and irreversible modifications, becoming a harmful and improper means for the health and well-being of the population. The creation of green urban spaces, besides the sustainable revitalization of existing public places, provides an improvement in the quality of life, environmental and social benefits. In view of this presented reality, the objective of this study was to discuss the importance of the plant nursery within the Teresina Botanic Garden, as an instrument to create green and green areas, providing sustainability within the city. For that, researches were carried out in scientific sources that portray this subject in addition to field research in the nursery of the Teresina Botanic Garden. It was observed that the nursery of seedlings of the Botanical Garden works as an important instrument in the reforestation of the city, in areas of parks, squares and revitalization projects, with the cultivation of native plants, adaptable to our climate. However, more infrastructure is needed in the park and dissemination of the nursery to greater spontaneous demand of the population.

KEYWORDS: Green areas. Afforestation. Sustainability.

\section{RESUMEN}

Las ciudades crecieron desordenadamente en las últimas décadas, en virtud del proceso de urbanización sin planificación y, consecuentemente, a la deforestación y la falta de reprogramación de nuevos espacios verdes. Por su parte, el ambiente viene presentando modificaciones importantes e irreversibles, convirtiéndose en un medio nocivo e inapropiado para la salud y el bienestar de la población. La creación de espacios urbanos arbolados, además de la revitalización sostenible de locales públicos existentes, proporciona una mejora en la calidad de vida, beneficios ambientales y sociales. En el marco de esta realidad presentada, el objetivo de este estudio fue discutir la importancia del vivero de plantas, dentro del Jardín Botánico de Teresina, como instrumento de creación de áreas verdes y arboladas, proporcionando sustentabilidad dentro de la ciudad. Para ello, se realizaron investigaciones en fuentes científicas que retratan tal temática además de investigación de campo en el vivero del Jardín Botánico de Teresina. Se observó que el vivero de mudas del Jardín Botánico funciona como un instrumento importante en la reforestación de la ciudad, en áreas de parques, plazas y en proyectos de revitalización, con el cultivo de plantas nativas, adaptables a nuestro clima. Sin embargo, es necesaria más infraestructura en el parque y divulgación del vivero para mayor demanda espontánea de la población.

PALABRAS CLAVE: Areas verdes. Reforestación. Sustentabilidad. 


\section{INTRODUÇÃO}

O processo de urbanização teve início em meados do século $X X$, no Brasil, a partir da industrialização, representando atualmente mais de $80 \%$ da população brasileira vivendo nas cidades, segundo dados do IBGE (2010). Isso consequentemente, trouxe alterações no meio natural, através da retirada da cobertura vegetal, para que estruturasse o ambiente àquela nova necessidade urbana (LIMA; AMORIM, 2016).

Isso aconteceu devido ao enfoque na valorização e expansão do uso da máquina, como os automóveis, durante o desenvolvimento das cidades, ocasionando o espraiamento urbano sobre áreas onde deveriam ser preservadas, como margens dos rios, encostas íngremes, áreas alagadiças. Diante disso, houve a modificação dos ecossistemas naturais que mantem a estabilidade e sustentabilidade das cidades (HERZOG; ROSA, 2010).

Além disso, com a expansão das cidades sem o planejamento adequado, surgiram vários problemas de infraestrutura, socioeconômicos, além de alterações ambientais que influenciaram direta ou indiretamente a qualidade de vida do homem urbano (LIMA; AMORIM, 2016).

De acordo com Rezende et al (2012), a urbanização trouxe reflexos negativos na vida dos moradores tanto na área sociocultural quanto na infraestrutura e saúde. Nesse quadro, com a degradação do meio ambiente e dos espaços arborizados para a instalação dos centros urbanos, houve a necessidade de criação de áreas verdes com o intuito de melhorar a qualidade de vida e o bem-estar social.

Os autores Silva e Moraes (2016) conceituam o espaço verde como sendo um ambiente agradável, onde possibilita a relação do homem com o meio natural além de reduzir impactos gerados pelo processo de urbanização. Para eles, o ambiente arborizado proporciona vantagens através da criação de microclima mais satisfatório, redução da poluição e preservação de espécies nativas no seu bioma original.

Segundo Schvarstzhaupt e Reis (2017), as áreas verdes trazem sensações positivas sobre o ser humano, influenciando no bem-estar individual, além de atuar como tranquilizantes e melhorar a função cognitiva. Conforme o mesmo autor, os efeitos benéficos da presença da vegetação em áreas residenciais, de comércio, em sistemas de tratamento de saúde, por exemplo, trazendo relaxamento, melhoramento da fadiga mental e a estabilidade dos parâmetros fisiológicos do corpo humano. 
Corroborando os efeitos positivos das áreas verdes nos centros urbanos, Lima e Amorim (2016, p. 70) apontam:

As áreas verdes assumem um papel muito importante nas cidades no que se refere à qualidade do ambiente, pois servem de equilíbrio entre a vida urbana e o meio ambiente quando esses espaços são utilizados e preservados para esse fim. Além disso, deveriam ser destinadas à recreação e ao lazer da população.

As áreas verdes, conforme Szeremeta e Zannin (2013), são locais de referência nos grandes centros urbanos, tanto pela função recreativa como esportiva, de sociabilização e ambiental. Cada vez mais se tem associado os espaços verdes a promoção da atividade física, pois essa prática, em um ambiente verde, estaria relacionada à motivação, uma vez que as pessoas se sentem mais satisfeitas em realizar atividade física nos espaços arborizados.

Além disso, a presença de ambientes arborizados nas proximidades das moradias reduz 0 impacto de eventos estressantes vivenciados por crianças em idade escolar, sendo apontado em pesquisa que crianças que mantinham contato com ambientes verdes apresentavam poucos episódios de patologias psíquicas e maior autoestima (SCHVARSTZHAUPT; REIS, 2017). Neste caso, há uma relação direta entre os efeitos do estresse e a vegetação, com os sentimentos de aflição e de autoestima, quando ausente.

Os autores Schvarstzhaupt e Reis (2017) mostram também como a vegetação nas áreas marginais das residências poderiam minimizar a fadiga mental e reduzir os níveis de violência doméstica. Outro estudo revela um número crescente de agressões e violência vivenciadas por mulheres em vizinhança sem vegetação e altos níveis de fadiga mental. Além disso, áreas mais pobres se mostram mais vulneráveis ao risco de fadiga psicológica crônica e, consequentemente, atos violentos.

Na saúde, a paisagem influencia na manutenção do bem-estar e equilíbrio fisiológico do organismo humano. De acordo com Schvarstzhaupt e Reis (2017), os pacientes no pósoperatório assistidos em um ambiente onde existe a presença de paisagem verde, apresentam taxas pressóricas menores e retardam a ansiedade, contribuindo para redução no uso de medicações e de seus efeitos colaterais.

Além disso, a vegetação influencia positivamente o desempenho acadêmico dos estudantes, proporcionando interação social, melhoria do funcionamento cognitivo, no aprendizado e compreensão do conteúdo (SCHVARSTZHAUPT; REIS, 2017). 
De acordo com Rezende et. al. (2012), a área verde configura-se como ambiente livre, público e com predominância de espaço plantado, apresentando as funções estética, ecológica e de lazer. Além disso, esse ambiente deve oferecer algum tipo de vegetação, de modo a criar locais agradáveis e harmônicos. Para a Organização Mundial de Saúde, o índice mínimo recomendado de área verde é de $12 \mathrm{~m}^{2}$ por habitante, no ambiente urbano (SILVA; MORAES 2016).

Para Silva e Moraes (2016), a prática e o uso da arborização nos centros urbanos trazem transformações morfológicas nos ambientes ocupados e ainda, englobam novas áreas, de modo diferente, ao espaço urbano. Então, a vegetação e o tratamento paisagístico, contribuem para rearborização desses ambientes contemporâneos, além de contribuir ecologicamente para o planeta.

As árvores apresentam funções ecológicas importantes como: a prevenção de erosões e assoreamento de corpos d’água; promovem a infiltração das águas das chuvas; capturam gases de efeito estufa; minimizam os efeitos das ilhas de calor (HERZOG; ROSA, 2010). Observa-se com isso, que os parques urbanos, por caracterizarem-se pela grande presença de árvores, tem um importante papel nos centros urbanos.

De acordo com Rezende et. al. (2012), os parques são equipamentos públicos difundidos a partir dos europeus diante de momentos historicamente específicos. Eles são caracterizados como um tipo de área verde na cidade, apresentando predominantemente vegetação como elemento integrante do ambiente construído e possuem funções importantes nas áreas do entretenimento, ambiente e estrutura urbana.

No entanto, conforme Farr (2013), os parques e as praças de bairro são negligenciados no planejamento urbano. Além disso, os parques pequenos dificilmente são criados e implantados em cidades existentes e ainda, muitas vezes, o preço do solo é frequentemente elevado e os terrenos de propriedade pública localizam-se em locais inadequados a implantação de um parque.

Tais áreas verdes, ao contrário, deveriam ser projetadas de modo a se conectarem, ampliando seus benefícios em potencial, sendo o somatório das mesmas maior que o somatório das partes quando isoladas. Esse cenário caracteriza a infraestrutura verde das cidades, que assim como a infraestrutura cinza (sistema viário, elétrico, esgotamento sanitário, dentre outros) é essencial para que a mesma apresente qualidade de vida para seus habitantes. 
Na última década, a infraestrutura verde está inserida nos planejamentos sustentáveis em várias cidades de muitos países. Trata-se de um conceito abrangente que emprega conhecimentos científicos e outras ferramentas de intervenção. Para Herzog e Rosa (2010, p.98-99):

Bem planejada, implementada e monitorada a infraestrutura verde pode se constituir no suporte para a resiliência das cidades. Pode ser um meio de adaptar e regenerar o tecido urbano de modo a torná-lo resiliente aos impactos causados pelas mudanças climáticas e também preparar para uma economia de baixo carbono. Ela aumenta a capacidade de resposta e recuperação a eventos climáticos, propicia mudança das fontes de energias poluentes ou de alto custo para fontes renováveis, promove a produção de alimentos perto da fonte consumidora, além de melhorar a saúde de seus habitantes ao possibilitar transportes ativos como caminhada e bicicleta.

A arborização urbana deve ser planejada de modo que tenha relevância na promoção de saúde e qualidade de vida de uma população. O sucesso de um projeto de arborização depende do compromisso e da conscientização do poder público e da sociedade, além de políticas públicas que incentivem a construção e revitalização dos espaços, de acordo com as necessidades dos seus frequentadores e comunidade em geral (SZEREMETA; ZANNIN 2013).

Diante desse panorama urbano, a cidade de Teresina, capital do Piauí, evidenciou a necessidade de espaços verdes em meados da década de 1960, tanto pelo melhoramento da qualidade de vida e do microclima quanto pela parte plástica que o tom esverdeado trazia para a cidade, recebendo o título de Cidade Verde (SILVA; MORAES, 2016).

No entanto, diante do intenso processo de urbanização da cidade entre 1980 a 2006, com crescimento de $140 \%$ da população urbana, houve um espraiamento da capital, e implantação de uma infraestrutura adequada as novas necessidades urbanas. Diante disso, Teresina perdeu o título de Cidade Verde, pelo desmatamento e diminuição das áreas verdes (MELO; BRUNA, 2009).

Atualmente, existem políticas públicas na capital do Piauí voltadas para educação ambiental dentro das escolas e de programa de arborização específico, conhecido como Teresina Mais Verde, para espaços públicos como avenidas, ruas e praças (SILVA; MORAES, 2016).

O programa "Teresina Mais Verde" foi criado em 2012 a fim de recuperar o título perdido pela diminuição da arborização local. A meta desse programa seria plantar, replantar e distribuir 150 mil mudas de árvores nativas, frutíferas e ornamentais na cidade (SILVA; MORAES, 2016). 
De acordo com Silva e Moraes (2016), os viveiros de plantas presentes em Teresina têm um importante papel no programa de arborização da cidade. Eles foram criados no atual Jardim Botânico, firmando-se na década de 1980, através de um convênio entre o Instituto Brasileiro do Meio Ambiente e dos Recursos Naturais Renováveis (IBAMA) e Prefeitura Municipal de Teresina, a fim de produzir mudas e proporcionar o reflorestamento da cidade. Na atualidade, existem três viveiros municipais que abastecem a cidade.

\section{OBJETIVO}

Esse estudo tem o intuito de discutir a importância do viveiro de plantas, dentro do Jardim Botânico de Teresina (PI), enquanto instrumento de criação de espaços verdes e arborizados, proporcionando sustentabilidade dentro da cidade.

\section{METODOLOGIA}

Trata-se de uma pesquisa descritiva com levantamento bibliográfico a partir de bancos de dados virtuais, em bibliotecas, no período de agosto a dezembro de 2017. Para esse estudo foram realizadas pesquisas em fontes científicas que retratam tal temática além de pesquisa de campo no viveiro do Jardim Botânico de Teresina.

\section{RESULTADOS}

A cidade de Teresina, capital do Estado do Piauí, localiza-se numa zona de transição entre o Semiárido nordestino e a Amazônia conhecida por Meio-Norte, com população de 814.230 habitantes, segundo dados do IBGE, em 2010.

Diante dessa localização geográfica, a cidade apresenta aspectos peculiares em relação à umidade relativa do ar, ao sistema de chuvas, à ausência de ventos e às temperaturas elevadas anualmente. Desta forma, a população sofre algum desconforto térmico sendo chamada muitas vezes de cidade quente (SEMPLAN, 2011).

Segundo a SEMPLAN (2011), outro aspecto relevante com relação ao clima de Teresina é a tendência para o aumento térmico, pois o elevado processo de urbanização provoca uma maior demanda na área da construção civil, geralmente com uso de materiais construtivos que absorvem calor, além do asfaltamento urbano, a falta de espaços livres, o consumo intenso de energia elétrica e a descarga de gases prejudiciais pelos veículos automotores. Isso provoca a formação das ilhas de calor, um grande problema climático das cidades. 
A capital Teresina, também conhecida como Cidade Verde (apelido apresentado pelo escritor Coelho Neto), vem perdendo sua característica pelo crescente processo de urbanização e desmatamento de áreas arborizadas, modificando sua particularidade enquanto espaço urbano verde (SILVA; MORAES, 2016).

As áreas verdes nos quintas das residências em Teresina, historicamente muito utilizadas com espécies frutíferas, vem se reduzindo ao longo do tempo, correspondendo em média a $20 \%$ das áreas edificadas. Segundo o IBGE (2010), a capital apresenta 72,3\% de domicílios urbanos em vias públicas com arborização e 5,8\% de domicílios urbanos em vias públicas com urbanização adequada.

Diante dessa perspectiva de melhoramento ambiental para Teresina, em 2006, através da lei 3.558, na qual restitui o plano diretor de Teresina para a Agenda 2015, um dos objetivos físicos-ambientais foi aumentar a cobertura vegetal e recuperar as áreas degradadas com o plantio de espécies nativas, através da criação de novos parques, praças e jardins, além de promover arborização de vias comes espécies adequadas e estimular o reflorestamento como alternativa ao desmatamento de espécies nativas.

O Jardim Botânico de Teresina (Figura 01), considerado como uma grande área de preservação permanente municipal da cidade, foi criado através da Lei Municipal em 1960, como Parque Ambiental de Teresina, na Zona Norte, recebendo atual enquadramento em 2011, com fins de pesquisa, além da produção de mudas e reflorestamento da cidade (SILVA; MORAES, 2016).

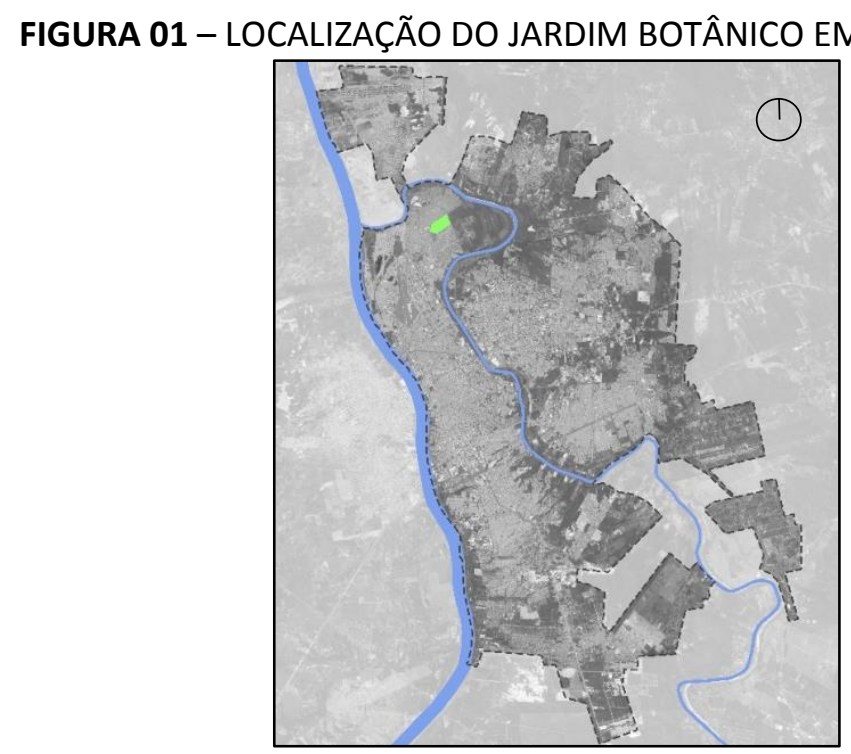

Fonte: Adaptado do Google Maps (2018). 


\section{Periódica Eletránica

Atualmente, o Jardim Botânico (Figura 02) constitui-se como uma grande área verde dentro da capital, abrigando espécies tanto da flora quanto da fauna local, além de possuir estruturalmente uma edificação com auditório e museu para exposição de aves empalhadas. Nas áreas externas, foram projetadas trilhas verdes, dentro do parque, com a função educativa e esportiva.

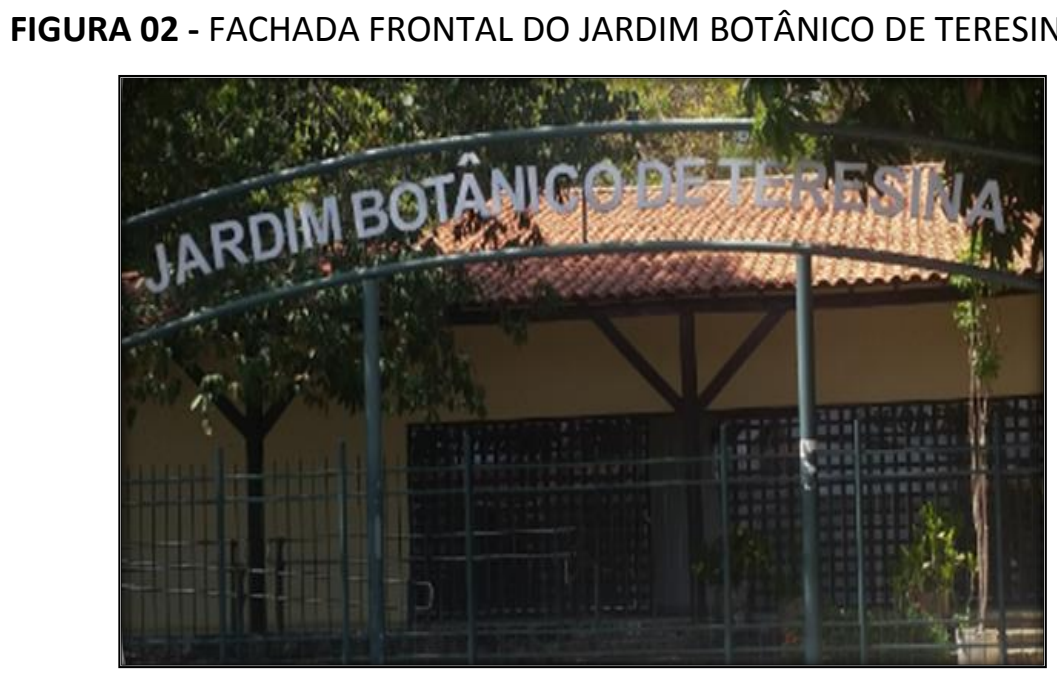

Fonte: Acervo Pessoal (2017).

Pela visita de campo constatou-se a presença de viveiros de plantas frutíferas, ornamentas e nativas dentro de toda a área do Jardim Botânico, onde toda a gestão é feita pela Prefeitura de Teresina, no Departamento de Arborização. Atualmente, contamos com três viveiros dentro da cidade, em diferentes zonas.

Além desses viveiros, de forma mais científica dentro do Jardim Botânico, existe uma área de trabalho e cultivo de espécies medicinais para fins de pesquisa onde a população poderá ter acesso caso tenha autorização prévia dos responsáveis administrativos.

O material para o plantio das mudas é fornecido pela Prefeitura da cidade e através de doações da iniciativa privada cuja matéria-prima é as plantas frutíferas da região. As sementes das árvores são plantadas em sacos plásticos para uso no reflorestamento e arborização de Teresina.

O trabalho da equipe do viveiro dentro do Jardim Botânico atua de forma a fornecer para a gestão municipal as mudas para plantio direto em praças, parques, canteiros centras nas vias; além de distribuir as plantas juntamente em associações de moradores, eventos e para a população em geral.

Atualmente, o município conta com um Programa chamado de Teresina Mais Verde, criado em 2013, sob a supervisão da Coordenação de Arborização da cidade, cuja finalidade é deixar a 
cidade mais arborizada e verde. Para o Coordenador do Programa de Arborização, a meta em 2016 foi distribuir 300 mil mudas em toda capital (SEMAM, 2016).

Ao final do ano de 2016, o município havia superado a meta inicial, distribuindo mais de 300 mil mudas conforme relatório apresentado pelo Coordenador desse Projeto. Para que essa meta fosse atingida, os responsáveis pelo trabalho realizaram várias ações externas, como o Caminhão Verde e outras de distribuição dentro dos bairros (SEMAM, 2016).

Observou-se que o viveiro de mudas do Jardim Botânico funciona como um instrumento importante no reflorestamento da cidade, em áreas de parques, praças e em projetos de revitalização, com o cultivo de plantas nativas, adaptáveis ao nosso clima.

Além disso, esse serviço não engloba ações macro paisagísticas de criação de áreas verdes, mas permite que o cidadão em seu ambiente domiciliar usufrua de uma arborização através da disponibilidade e acessibilidade dessas mudas pelo próprio incentivo do Programa de Arborização da cidade.

Então, cada cidadão tem disponibilidade de adquirir 10 unidades de plantas, sejam nativas, ornamentais ou frutíferas (Figura 03). As plantas medicinais poderão ser cedidas após autorização da Administração do serviço (Figura 04). Desta forma, é possível criar mais espaços verdes na cidade de Teresina tanto através da iniciativa pública em espaços urbanos quanto pela população, em seu microespaço interno.

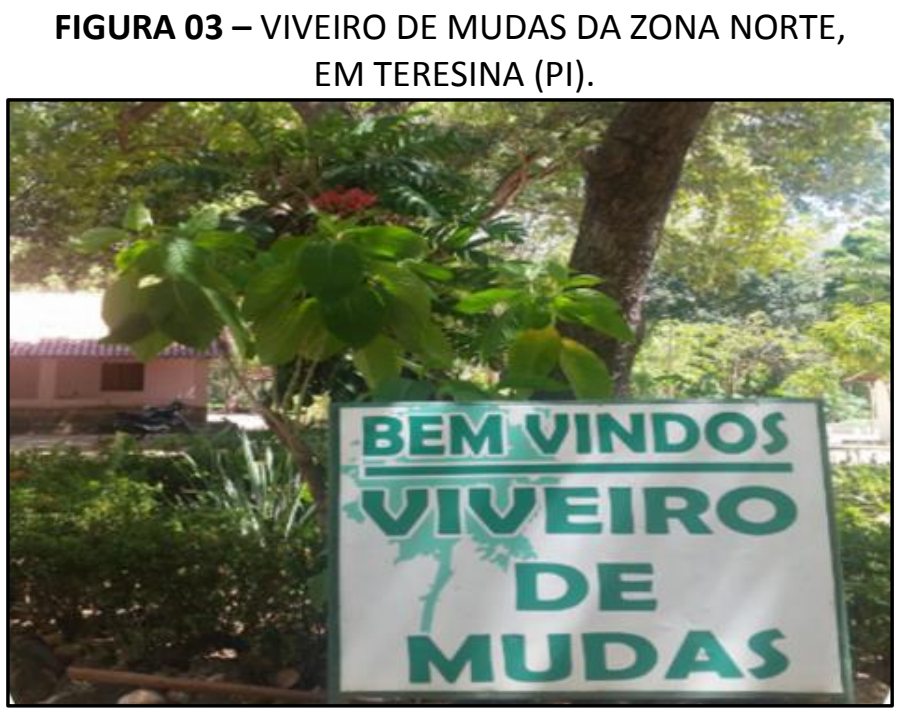

Fonte: Acervo Pessoal (2017). 
FIGURA 04 - VIVEIRO DE PLANTAS MEDICINAIS DA ZONA NORTE, EM TERESINA (PI).

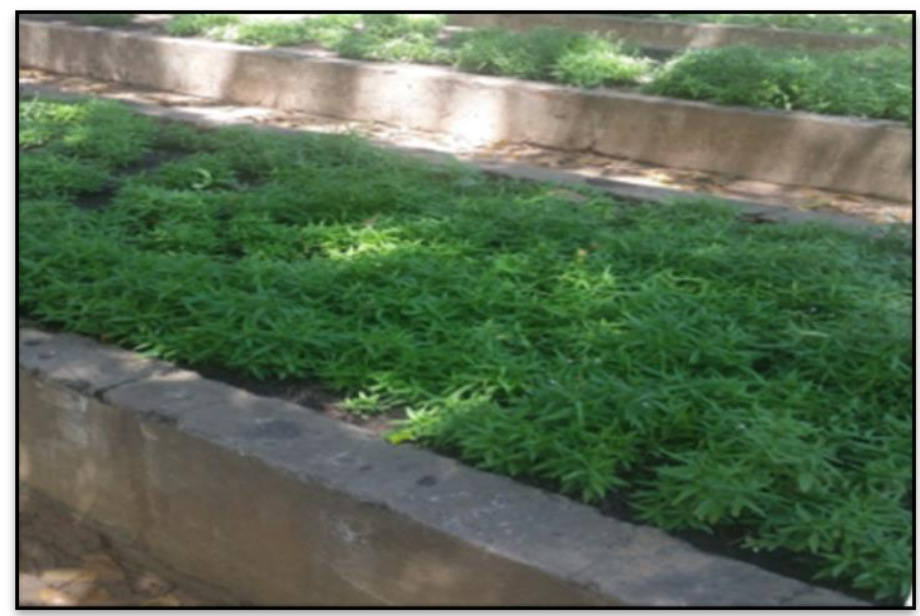

Fonte: Acervo Pessoal (2017).

Em relação a conservação e estruturação, o Jardim Botânico de Teresina necessita de maiores cuidados e investimentos. Na visita ao local, encontrou-se um acesso inadequado aos portadores de necessidades especiais (Figura 05), além de um auditório em péssimas condições de uso e um museu apresentando diversas manifestações patológicas em sua estrutura.

FIGURA 05 - ACESSO AO JARDIM BOTÂNICO, EM TERESINA (PI).

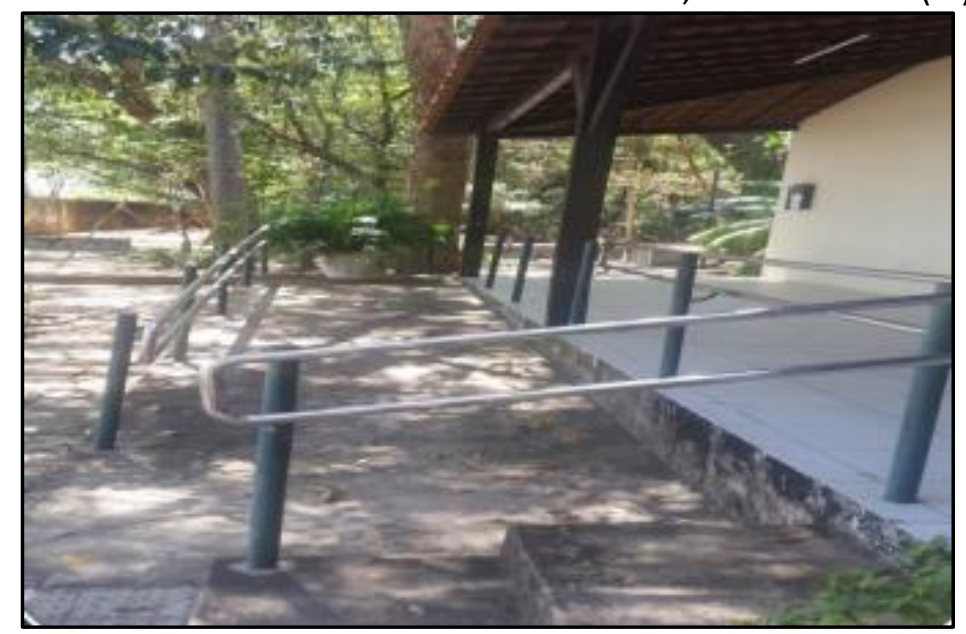

Fonte: Acervo Pessoal (2017).

Além disso, as trilhas que dava acesso ao parque não tinham a devida identificação e não ofereciam segurança aos visitantes (Figura 06). Desta forma, tratando-se de um referencial de destaque como área verde e de importância ambiental e científica, esse espaço não está adequado para receber o público de modo satisfatório. 


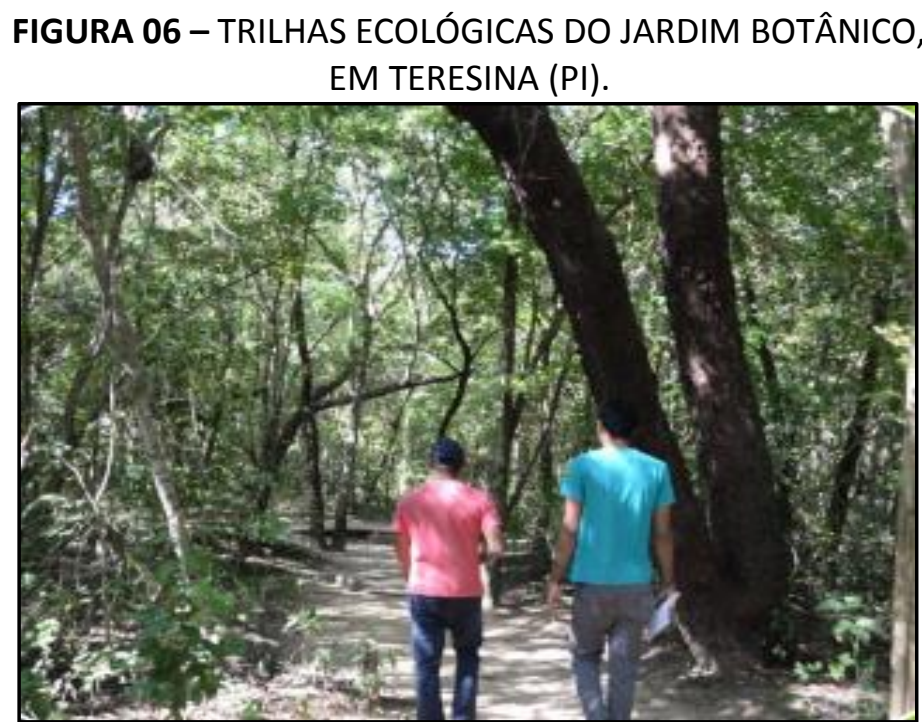

Fonte: Acervo Pessoal (2017).

Para maior demanda e visita ao local, é necessária mais estruturação do Parque e divulgação da proposta de doação e conservação das espécies nativas da flora por parte do poder público, pois a população da cidade poderia procurar em maior número o serviço, e consequentemente arborizar de forma significativa e individual a cidade.

\section{CONCLUSÃO}

Esse estudo mostrou a importância dos viveiros de plantas na criação de espaços verdes urbanos em Teresina, tanto para melhoramento da qualidade de vida, quanto para promoção da sustentabilidade.

O viveiro do Jardim Botânico da cidade, através de políticas públicas locais, funciona como um instrumento essencial de distribuição de árvores para fins de reflorestamento, além de funcionar como meio de preservação das espécies locais. Sendo assim, tanto a inciativa pública quanto a sociedade civil são fundamentais no melhoramento ambiental da cidade, proporcionando mais áreas verdes e arborizadas.

No entanto, existe a necessidade de melhoramento estrutural e de acesso ao espaço público presente dentro do Parque, para que a população utilize essa grande área verde como opção de lazer, cultura e entretenimento.

\section{REFERÊNCIAS BIBLIOGRÁFICAS}

FARR, Douglas. Urbanismo Sustentável: desenho urbano com a natureza. Porto Alegre: Bookman, 2013. 
HERZOG, C. P.; ROSA, R. Z. Infraestrutura verde: sustentabilidade e resiliência para a paisagem urbana. Revista LABVERDE, v.1, p.93-115, 2010.

IBGE, 2010. Sinopse do Censo Demográfico 2010. Disponível em: <https://censo2010.ibge.gov.br/sinopse/index.php?dados=8>. Acessado dia 26 de out. de 2017.

IBGE, 2010. Panorama de Teresina. Disponível em: < https://cidades.ibge.gov.br/brasil/pi/teresina/panorama>. Acessado dia 26 de out. de 2017.

LIMA, V. AMORIM, M. C. C. T. A importância das áreas verdes para a qualidade ambiental das cidades. Revista Formação, nำ13, p. 139 - 165, dez.2016.

MELO, Constance de Carvalho Correia Jacob; BRUNA, Gilda Collet. Desenvolvimento urbano e regional de Teresina, Piauí, Brasil e sua importância no atual quadro de influência na Rede Urbana Regional no Brasil. In: 1 ㅇ Congresso de Desenvolvimento regional de Cabo Verde - 15응 Congresso da APDR- 2ㅇ Congresso Lusófono de Ciência Regional- 3 Congresso de Gestão e Conservação da Natureza. Cidade do Cabo, Cabo Verde: UniPiaget, 2009. P. 3588-3611.

REZENDE, P. S.; SOUZA, J. R.; SILVA, G. O.; RAMOS, R. R.; SANTOS, D. G. Qualidade ambiental em parques urbanos: levantamento e análises de aspectos positivos e negativos do Parque Municipal Victório Siquierolli, Urbelândia (MG). OBSERVATORIUM: Revista Eletrônica de Geografia, v. 4, n.10, p. 53-73, ago.2012.

SCHVARSTZHAUPT, C. C.; REIS, A. T. Vegetação Urbana e instrumentos legais. Anais XVII ENANPUR. São Paulo, 2017.

SEMAM, 2016. Projeto de Arborização supera meta de plantio e distribuição de mudas em Teresina. Disponível em: < http://www.portalpmt.teresina.pi.gov.br/noticia/Projeto-dearborizacao-supera-meta-de-plantio-e-distribuicao-de-mudas-em-Teresina/12992>. Acessado dia 26 de out. de 2017.

SILVA, S. L.; MORAES, M. V. A. R. Percepção Ambiental e Arborização Urbana em Teresina, Piauí. Revista Equador (UFPI), Vol. 5, № 3 (Edição Especial 02), p. 320 - 339, jul.2016.

SZEREMETA, B. ZANNIN, P. H. T. A importância de parques urbanos e áreas verdes na promoção da qualidade de vida em cidades. R. Ra'e Ga, Curitiba, v.29, p.177-193, dez/2013.

TERESINA (Município). Lei n. 3.558 de 20 de outubro de 2006. Reinstitui o Plano Diretor de Teresina, denominado de Plano de Desenvolvimento Sustentável. Ementa. 2006. 